\title{
Substantiation of technological approaches to the creation of functional products based on milk and carrot compositions
}

\author{
Irina Bibik ${ }^{1, *}$, Sergey Doronin ${ }^{1}$, and Sergey Dotsenko ${ }^{1}$ \\ ${ }^{1}$ Far Eastern State Agrarian University, 86, Politeknicheskaya Str., Blagoveschensk, Russia
}

\begin{abstract}
Scientific research and practice show that a certain part of the population of the Russian Federation is deficient in essential food nutrients, such as $\beta$-carotene, vitamin $\mathrm{C}$ and bioflavonoids. In this regard, there is a problem of creating food products with a functional orientation of an expanded range. It is also important that such products have at least one of the specified physiological effects, the list of which is given in the Russian national standard - GOST R 54059-2010. As a working hypothesis, it was assumed that there is a possibility and feasibility of extracting $\beta$-carotene from carrots by the fatty component of cow's milk, followed by an increase in its content in milk lipid-containing food systems by separation. Implementation of the developed technological system for preparing a protein-lipid dispersed system based on cow's milk and carrots made it possible to obtain creamy-carrot compositions with a mass fraction of fat in the range of $10-20 \%$. Thermal acid coagulation of proteins in such food systems with a solution of ascorutin made it possible to obtain orange-colored coagulates containing the antioxidant complex - $\beta$-carotene + vitamin $\mathrm{C}+$ rutin. Based on the results of the studies, it was concluded that these products make it possible to expand the range of functional food products with a given physiological effect.
\end{abstract}

\section{Introduction}

One of the problems of the state policy in the field of healthy nutrition of the population of the Russian Federation has been and remains today the preservation and strengthening of the health of citizens, as well as the prevention of diseases caused by inadequate and unbalanced nutrition. At the same time, the relevant Convention provides for the development of the production of food products enriched with irreplaceable components, functional products, dietary products (therapeutic and prophylactic), etc.

However, as noted by numerous studies of domestic scientists, a certain part of the country's population experienced and is experiencing an acute deficiency in essential nutrients of food [1-4].

This fact explains the presence of diseases associated with a deficiency of physiologically functional food ingredients in certain categories of the population and

\footnotetext{
* Corresponding author: bibik7irina@mail.ru
} 
workers, which, in accordance with the national standard (GOST R 52349-2005) include biologically active and physiologically valuable ingredients (FVI) in the form of certain substances or their complexes.

In this regard, the problem of creating innovative products of a functional orientation of an expanded assortment is relevant and of great economic importance.

The aim of the research is to substantiate technological approaches to creating a product based on a creamy carrot composition of a given composition and properties.

Research objectives:

1) substantiate the possibility and feasibility of obtaining a protein-lipid dispersed system (PLDS) using a milk-carrot composition as a basis for the preparation of functional food products of an extended range with a given physiological effect;

2) develop a schematic diagram of the preparation of PLDS and give a biochemical characteristic of the composition of coagulation systems obtained on its basis.

As an object of research, we used cream enriched with $\beta$-carotene with a mass fraction of fat $\mathrm{MFF}=10,15$ and $20 \%$, obtained in accordance with the developed technological scheme. And an aqueous solution of ascorutin was used as a coagulant.

\section{Materials and Methods}

As noted in [3], "the achieved level of enzymatic catabolism, which is provided by physiological norms of complete proteins, essential lipids and carbohydrates, as well as essential vitamins and minerals, is a condition for the normal functioning of the physiological antioxidant system".

The authors of [3], giving a list of direct and indirect antioxidants, note the high efficiency of their use in the so-called "antioxidant systems", especially in combination with flavonoids. The advantage of such systems is caused by the so-called synergism in double, triple and more complex combinations.

Thus, it is important not to simply enrich food systems with individual essential ingredients, but to saturate them in significant quantities with complexes that have given effects.

At the same time, the correct choice of the enriched and enriching objects, taking into account the conditions of transformation of raw materials and used components, is of great importance. Thus, the milk base with the inclusion of a plant component in its composition is most often used as an enriched object [5 - 7].

At the same time, carrots $[8,9]$, pumpkin and brown algae [10, 11], as well as sea buckthorn and products of its processing [12] are widely used as an enriching carotenecontaining component.

There are also known works in which an attempt was made to enrich food systems with a synthetic heterocyclic organic compound of selenium, "Seleksen", as well as a vitamin premix - VP 963/7, in the form of dairy, bakery and sausages [13].

In the process of substantiating technological approaches to the creation of functional products based on milk-carrot compositions, the basic principles set forth in the works [14, 15] were taken into account.

Fig. 1 shows a schematic process flow diagram of the preparation of a protein-lipid dispersed system, by separating which cream with MFF $=10-20 \%$ was obtained. 


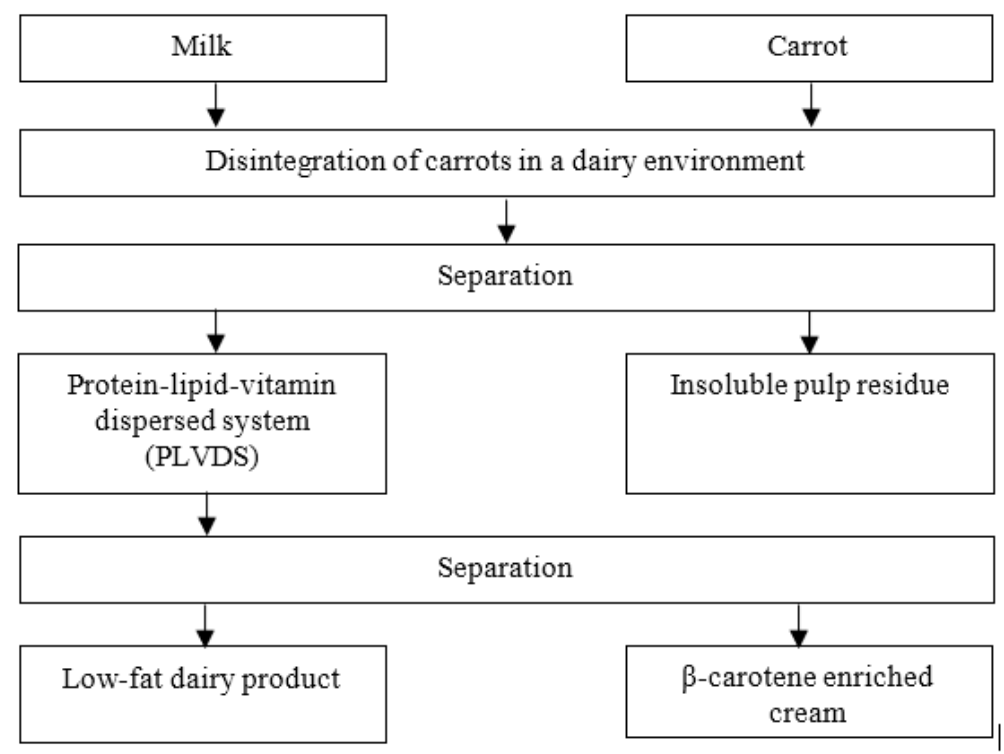

Fig. 1. Basic technological scheme for the preparation of PLDS and cream product.

As follows from the presented scheme, the technological approach to the production of PLDS is based on the principle of extracting $\beta$-carotene by the fatty component of cow's milk, followed by separation of this component, with the mass fraction of fat $-\mathrm{MFF}=10$, 15 and $20 \%$.

Fig. 2 shows a schematic process flow diagram for obtaining curd products with different biochemical composition and fortified whey by thermoacid coagulation of proteins with a solution of ascorutin in a mild mode.

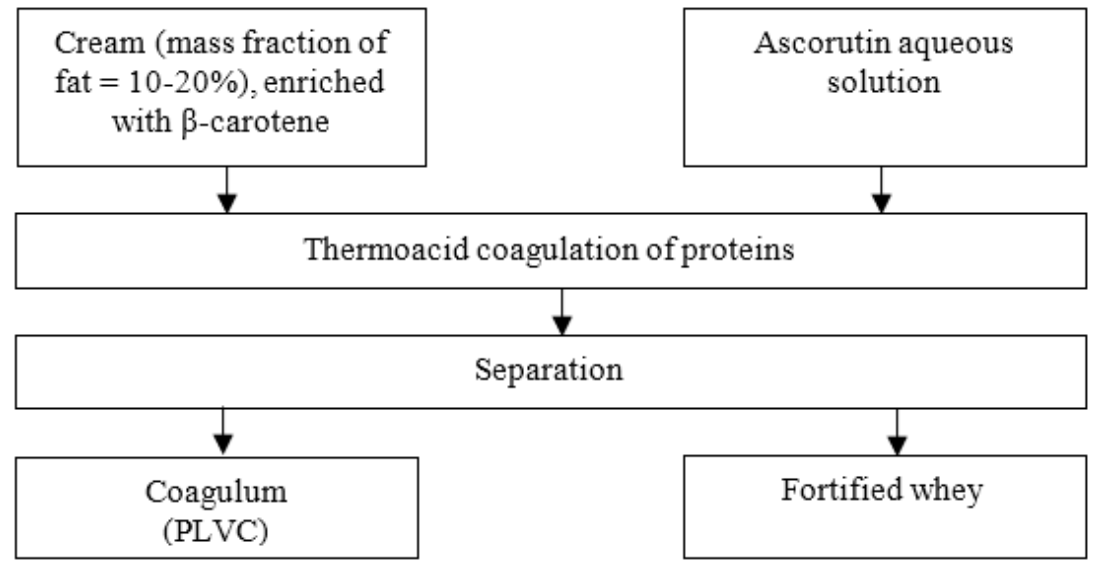

Fig. 2. Principal technological scheme for obtaining protein-lipid-vitamin coagulum.

\section{Results}

Table 1 shows the composition of the obtained products in the form of an orange colored mass and fortified whey. 
Table 1. Biochemical composition of PLVC.

\begin{tabular}{|c|c|c|c|c|c|c|c|c|}
\hline \multirow[t]{3}{*}{ No. } & \multirow[t]{3}{*}{ Products } & \multicolumn{6}{|c|}{ Content } & \multirow{3}{*}{$\begin{array}{c}\text { Energy } \\
\text { value, } \\
\mathrm{kcal} / 100 \mathrm{~g}\end{array}$} \\
\hline & & \multicolumn{5}{|c|}{ basic substances, $\%$} & vitamins, $\mathrm{mg} / 100 \mathrm{~g}$ & \\
\hline & & water & proteins & fat & \begin{tabular}{|c|} 
carboh \\
ydrate \\
s
\end{tabular} & minerals & $\beta$ - carotene $\mathrm{C}$ & \\
\hline 1 & $\begin{array}{l}\text { Creamy carrot curd mass - } \\
\text { coagulum: }\end{array}$ & & & & & & & \\
\hline 1.1 & $\begin{array}{l}\text { based on cream with MFF } \\
=10 \%\end{array}$ & 65.0 & 12.2 & 20.0 & 1.8 & 1.0 & 10.0 & 236.0 \\
\hline 1.2 & $\begin{array}{l}\text { based on cream with MFF } \\
=15 \%\end{array}$ & 58.6 & 14.1 & 25.3 & 2.0 & 1.0 & 12.0 & 292.1 \\
\hline 1.3 & $\begin{array}{l}\text { based on cream with MFF } \\
=20 \%\end{array}$ & 52.9 & 16.2 & 28.1 & 2.8 & 1.0 & 14.0 & 330.9 \\
\hline 2 & Fortified whey & 94.0 & 0.8 & 0.2 & 4.2 & 0.8 & 0.5 & 20.8 \\
\hline
\end{tabular}

* $-\%$ from the daily norm of physiological need

Analysis of the data presented in the table shows that the resulting food systems in the form of curd mass contain a complex of essential nutrients $\beta$-carotene + vitamin $C+$ rutin, which has synergistic effects and antioxidant activity [4].

The resulting products served as the basis for the creation of functional food products of an extended range with a given physiological effect [16].

In the process of ongoing research, a method for the preparation of a functional weight pate was also developed.

The development relates to the food industry and, in particular, to methods of preparing pate products.

A known method of making pate, including the preliminary preparation of liver and soybean raw materials, followed by mixing it with a lipid component in the form of fat, as well as with other components and fat-soluble vitamins $\mathrm{E}$ and $\beta$-carotene of artificial nature (Kozmava A.V. et al. Production technology of pates and minced meat. Rostov-on-Don, 2002. P. 44.).

The disadvantages of this method are, firstly, the relatively low content of polyunsaturated fatty acids due to the use of refined bone fat, imbalance of lipids for linoleic and linolenic fatty acids. Secondly, the use of vitamin E and $\beta$-carotene of artificial, i.e. synthetic nature of origin (they are obtained from petrochemical products) is not advisable both because of the difference in the structure of molecules in comparison with natural ones, and because of the inefficiency of their assimilation by the human body.

There is also known a method of making a pate, including obtaining minced meat based on a liver-meat component, a protein milk component and a lipid component in the form of oil components of animal (butter) and vegetable origin, as well as other components (Kozmava A.V. et al. Production technology of pates and minced meat. Rostov-on-Don, 2002. P. 41 - 43.)

The disadvantages of this method are relatively low consumer properties: the absence of vitamins $\mathrm{E}, \mathrm{C}, \mathrm{P}$ and $\beta$-carotene as a set of physiologically functional ingredients that provide the effect of maintaining the activity of the cardiovascular system (GOST R-540592010).

In addition, the use of butter and sunflower oil does not give a rational ratio of $\mathrm{C}_{18: 2}$ : $\mathrm{C}_{18: 3}=[(7.0-7.5): 1.0]$, as well as a rational ratio of protein: fat $=1: 1$, according to the formula of balanced nutrition.

The objective of the present invention is to obtain a weight pate with relatively high consumer properties that fully meet the requirements of the Russian national standards GOST R-52349-2005 and GOST R-54059-2010.

The technical result consists in the fact that this method allows obtaining a product in the form of a weight pate with significant concentrations of physiologically functional 
ingredients (PFI) with a given physiological effect of maintaining the activity of the cardiovascular system (CVS).

This is achieved by the fact that minced meat is obtained on the basis of the leaver-meat component, the protein milk component and the lipid in the form of oil components of animal and vegetable origin, as well as the egg mixture, fried onions, spices and materials. A protein-vitamin coagulum obtained by thermoacid coagulation of proteins in a creamycarotene-containing dispersed system with a solution of ascorutin is used as a protein-milk component, while cream-carrot, or creamy-pumpkin, or creamy-sea buckthorn is used as a creamy-carotene-containing dispersed system, and a blend based on soybean and corn oils, taken in a weight ratio of $70 \%: 30 \%$ is used as a lipid component. And $\beta$-carotene contained in the blend is extracted from the pulp of carrots without a core or pumpkin pulp, or the pulp of sea buckthorn fruits.

Fig. 3 shows a technological scheme for the preparation of functional weight pate.

On the basis of cream and pulp of carotene-containing raw materials, disintegration is carried out in a creamy dispersed medium in order to extract their lipid component of fatsoluble $\beta$-carotene from the pulp of carotene-containing raw materials. The so-called pulp, an insoluble residue, is separated from the resulting suspension to obtain a protein-lipidvitamin dispersed system (PLVDS). In PLVDS, thermoacid coagulation of protein substances is carried out with a solution of ascorutin. The obtained protein-lipid-vitamin coagulum (PLVC) containing significant concentrations of PFI, rational ratio of protein and fat $(\mathrm{P}: \mathrm{F})$, as well as linoleic and linolenic fatty acids $-\mathrm{C}_{18: 2}: \mathrm{C}_{18: 3}$, with a weight ratio of $32.5 \%$ mixed and chop with the liver-meat component $(32.5 \%)$, a blend of soybean and corn oils enriched with $\beta$-carotene extracted from the pulp of the corresponding fruits $(10 \%)$, egg mixture $(10 \%)$, fried onions $(3 \%)$, spices and materials (salt, sugar, pepper, etc.) $(2 \%)$, getting minced pate, which is laid in molds, baked according to the traditional scheme; cooled, packaged and sold to the consumer.

Comparative biochemical composition of pates is shown in Table 2.

Table 2. Comparative biochemical composition of pates.

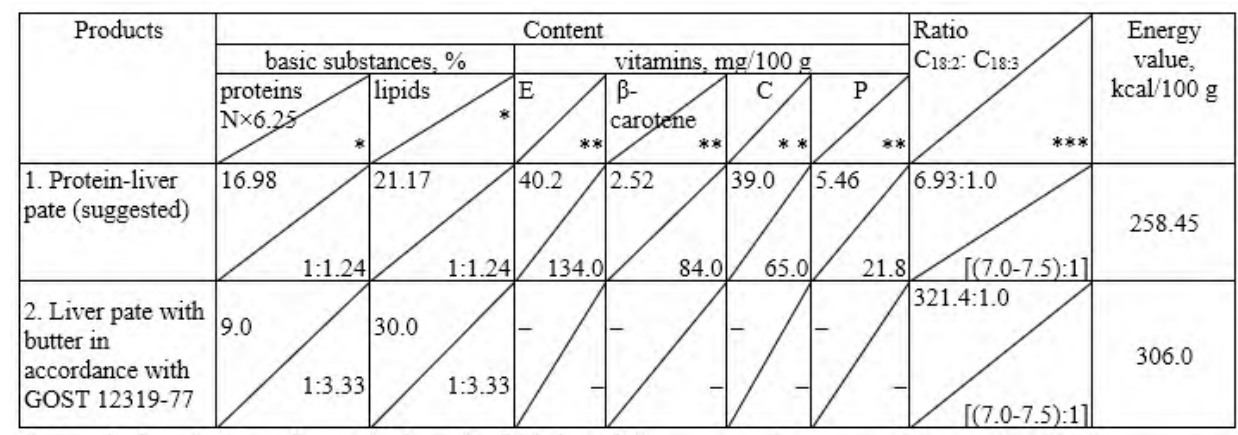

*- protein:fat ratio (according to the formula of a balanced diet $\mathrm{P}: \mathrm{F}=1: 1$ )

$* * \ldots$ from the daily norm of physiological need

*** - recommended ratio according to daily norm of physiological need

Analysis of the data given in Table 2 shows that the weight pate obtained by the innovative method meets the requirements of national standards: GOST R 52349-2005 and GOST R-54059-2010 for consumer properties and, in particular, for the content of PFI vitamins $\mathrm{C}, \mathrm{P}, \mathrm{E}$ and $\beta$-carotene according to the rational ratio of $\mathrm{P}: \mathrm{F}=1: 1.24$ according to the balanced nutrition formula, as well as according to the rational ratio of $\mathrm{C}_{18: 2}: \mathrm{C}_{18: 3}=$ 6.93:1 (close to [(7.0 - 7.5)]:1.0).

In this regard, an innovative weighted pate can be classified as a functional product with a predetermined effect of maintaining the activity of CVS with high consumer properties, 
with a code designation:

- vitamin C (V-I-1BE GOST R-54059-2010);

- vitamin P (flavonoid) (V-I-5BE GOST R-54059-2010);

- vitamin E (V-I-1BE GOST R-54059-2010);

- PUFAs $\mathrm{C}_{18: 22}: \mathrm{C}_{18: 3}$ (V-II-2;3 GOST R-54059-2010).

- carotenoids (V-I-1BE GOST R-54059-2010).

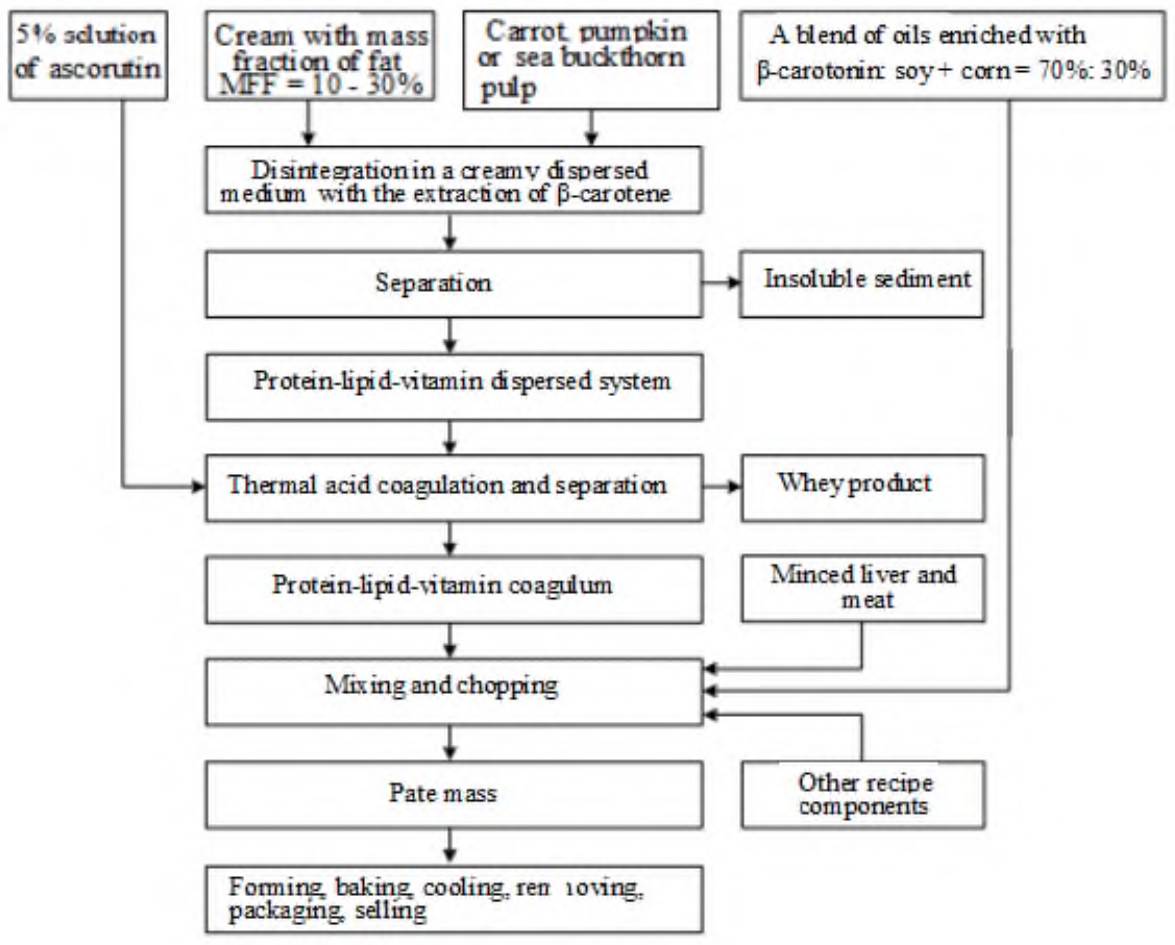

Fig. 3. Method of preparation of functional weighted pate.

\section{Discussion}

On the basis of cream, for example, with a protein content of $2.8 \%$, fat $20 \%$, fruit pulp of the Nantes, Chantone, Losinoostrovskaya varieties, for example, Vitaminnaya pumpkin varieties, a creamy pumpkin suspension enriched with $\beta$-carotene is obtained by disintegration. An insoluble pumpkin-creamy residue is separated from the suspension, on the basis of which, for example, a creamy-pumpkin-chocolate paste is then prepared. In the resulting PLVDS, thermoacid coagulation of protein substances is carried out, for example, with a $5 \%$ solution of ascorutin, as a result of which a protein-vitamin coagulum (PVC) is formed. PVK is separated from the whey product and brought to the required moisture content, providing significant concentrations of PFI in the resulting coagulum.

PVK in a mass fraction of $32.5 \%$ is mixed and chopped, for example, for 6 minutes with a previously obtained liver-meat component $=32.5 \%$, a blend of oils enriched with $\beta$ carotene $=10 \%$, egg mixture $=10 \%$, fried onions $=3 \%$, spices and materials $=2 \%$, getting minced meat in the form of a pate. The resulting mass is poured into molds, baked, for example, for $2-3$ hours at a temperature of $90^{\circ} \mathrm{C}$ in the first hour, up to $120^{\circ} \mathrm{C}$ in the second and $145^{\circ} \mathrm{C}$ in the third (up to a temperature inside the loaf equal to $72{ }^{\circ} \mathrm{C}$ ). Then the pate is 
cooled at $\mathrm{t}^{\mathrm{o}}=0-4{ }^{\circ} \mathrm{C}$ to $\mathrm{t}^{\mathrm{o}}=0-8^{\circ} \mathrm{C}$ inside the loaf. After that, it is packaged and sold to the consumer.

A method of preparing a functional pate, characterized by the fact that minced meat is obtained on the basis of a liver-meat component, a protein dairy component and a lipid component in the form of oil components of animal and vegetable origin, as well as an egg mixture, fried onions, spices and materials, while a protein-vitamin coagulum obtained by thermoacid coagulation of proteins in a creamy-carotene-containing dispersed system with a solution of askorutin is used as a protein milk component, while a creamy-carrot, or a creamy-pumpkin, or a creamy-sea buckthorn is used as a creamy-carotene-containing disperse system. A blend based on soybean and corn oils, taken in a ratio of $70 \%: 30 \%$ is used as lipid component, and the $\beta$-carotene contained in the blend is extracted from the pulp of carrots without a core or pumpkin pulp, or the pulp of sea buckthorn fruits.

\section{Conclusion}

It has been established that the proposed innovative approaches make it possible to extract $\beta$-carotene from carrots by the fatty component of cow's milk with the subsequent production of cream products enriched with carotenoids with different mass fractions of fat by separating PLDS.

Carrying out thermoacid coagulation of proteins in the obtained food systems using ascorutin provides food systems with the presence of an antioxidant complex with a given physiological effect determined by the national standard - GOST R-54059-2010.

At the same time, the creation of such products using innovative technologies is possible only by obtaining and maintaining significant concentrations of physiologically functional food ingredients (PFFI) at the appropriate stages of technological and physicochemical transformation of raw materials.

\section{References}

1. V.A. Tutelyan Nutrition and health Food industry, 5, 5-6 (2004)

2. A.F. Doronin, B.A. Shenderov Functional nutrition, 295 (2002)

3. A.D. Durnev, L.A. Oganesyan, A.B. Lisitsyn Functional food products Storage and processing of agricultural raw materials, 9, 15-21 (2007)

4. A.V. Shabrov, V.A. Dadali, V.G. Makarov. Biochemical bases of the action of food microcomponents 189 (2003)

5. L.V. Golubeva, E.I. Melnikova, E.B. Tereshkova Vegetable raw materials in milkcontaining dessert products Dairy Industry, 2,56 57 (2006)

6. S.G. Kozlov Research and development of technologies for whey gel-like products using plant raw materials: abstract of thesis of doct. tech. sciences 40 (2008)

7. L.N. Shatnyuk, T.V. Spiricheva Scientific aspects of the use of innovative ingredients in the production of specialized food products Food ingredients. Raw materials and additives, 2, 15-18 (2010)

8. S.M. Dotsenko, I.V. Bibik. Scientific basis for the creation of functional food products using biologically active raw materials of the Far Eastern Region, 293 (2014)

9. N.N. Tipsina, E.A. Tipsin The use of carrot powder in the food industry Vestnik of Krasnoyarsk State Agrarian University, 4. 257-261 (2014)

10. E.T. Novitskaya. Technology of forming the quality of emulsion nectars based on pumpkin (CUCURBITA MELON) with the addition of juice of honeysuckle berries, 
lemongrass, mountain ash, rose hips: abstract of thesis of Cand. tech. sciences, 24.(2010)

11. L.N. Stodolnik Substantiation and development of the technology of carotenecontaining products using brown algae for the production of flour confectionery products and their commodity assessment: abstract of thesis of Cand. tech. sciences, 24 (2014)

12. V.I. Bobchenko Development of technology and commodity assessment of ice cream using processed plant materials containing functional ingredients: abstract of thesis of Cand. tech. sciences, 24 (2018)

13. N.L. Naumova Scientific substantiation and practical aspects of the development of functional food products with antioxidant properties: abstract of thesis of doc. tech. sciences, 34 (2017)

14. N.N. Lipatov, T.Yu. Sazhinov, O.I. Bashkirov Formalized analysis of amino and fatty acid balance of raw materials, promising for the design of baby food with given food adequacy / Storage and processing of agricultural raw materials, 8, 11-14 (2001)

15. L.G. Ipatova, A.A. Kochetkova, A. Nechaev New directions in the creation of functional fatty products 1, 12-14 (2007)

16. S.V. Doronin RF patent 2681155 Method of obtaining functional products authors and others. Publ. in B.I. 7 dated 04.03.2019 